\title{
Population Dynamics and Possible Management Options for the Rock Dassie Procavia capensis Population in the Tsitsikamma Coastal National Park
}

\author{
N. FAIRALL and N. HANEKOM
}

Fairall, N. and N. Hanekom. 1987. Population dynamics and possible management options for the rock dassie Procavia capensis population in the Tsitsikamma Coastal National Park. - Koedoe 30: 139-148. Pretoria. ISSN 0075-6458.

A demographic study of the rock dassie population in the Tsitsikamma Coastal National Park rest camp has provided data that is used to construct a simple simulation model and it is applied to evaluate different management strategies for the rock dassie population.

Key words: Tsitsikamma, Procavia capensis, population biology, simulation model, management.

N. Fairall, Mammal Research Institute, University of Pretoria, Pretoria, 0002 Republic of South Africa; N. Hanekom, Tsitsikamma National Park, P.O. Storms River, 6308 Republic of South Africa.

\section{Introduction}

The Tsitsikamma Forest and Coastal National Parks are situated on the southern coast of the Republic of South Africa (Fig. 1) and was primarily intended to conserve the forest and marine habitat of the region. The most conspicuous mammal of this park, the rock dassie Procavia capensis (Pallas, 1766) is not typical of either of the above habitats.

It represents a ubiquitous genus whose range extends throughout Africa and through the rift valley into Israel and Syria. In the Tsitsikamma region small colonies of rock dassies occur at various points along the coast, where suitable shelter is available. They occupy the open land between the sea and the closed evergreen forest, never moving into the latter, which does not constitute a suitable habitat. One such rock dassie colony occurs in the rest camp of the Tsitsikamma Coastal National Park (TCNP). This group went through a period of rapid growth in numbers between 1975 and 1982. Similar trends have occurred in other areas along the south Cape coast (pers. obs.) as well as in other areas within their distributional range in the past, and fears were expressed that the increased numbers would lead to irreparable damage of the indigenous vegetation in the TCNP rest camp. Problems were also experienced due to the animals being fed by the public, becoming tame, and eventually entering the huts and biting the tourists. Elsewhere 
in South Africa, the rock dassie poses an agricultural problem competing with domestic livestock for available grazing (Hanse 1962; Kolbe 1967). The population dynamics of $P$. capensis are unknown and, therefore, the rest camp population which was relatively easy to study because of the limited foraging range (see Fig. 1) and tameness of the animals in this area was used with the specific purpose of developing a demographic model on which management decisions could be based. This paper is an attempt to review the results of the study in terms of this purpose, using a simple model that requires only a programmable calculator to operate.

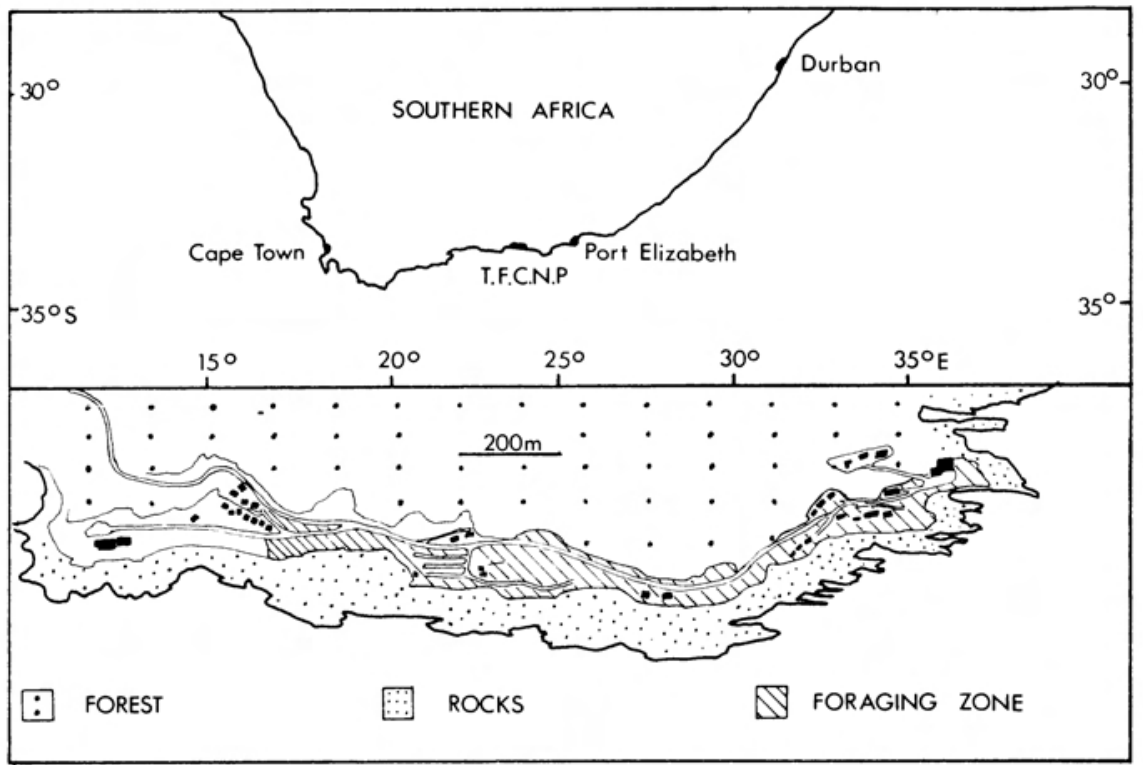

Fig. 1. The position of the study area and a detailed sketch of the terrain illustrating the limited area available to the rest camp population. Black squares in the foraging zone represent buildings of various kinds.

\section{Methods}

Reliable age determination of rock dassies would require capture and handling of the animals. This was considered to be impracticable. Rock dassies are seasonal breeders, all the young being born in less than one month, and as the animals could (from a distance) be visually grouped into one of the two classes, namely, $>1$ and $<1$ year, they were censussed in these groupings. Age of captured rock dassies was determined according to Fairall (1980).

Quarterly population censuses were conducted during December, February, June and September from 1979 to 1986. Each census comprised a set of $10-15$ counts and was done as described by Fairall \& Crawford (1983) whose work had shown that the census method based on Robson \& Whitlock (1964) was reliable. The values for all the censuses were employed in assessing the accuracy of the technique used, while only the December (postbirth pulse) and September 
(prebirth pulse) counts were used to calculate the population growth variables. This allows the assessment of annual juvenile recruitment (natality) and annual mortality, respectively.

The age structure of the population as well as age-specific sex ratios were determined from data collected from 48 rock dassies captured for various reasons (Crawford \& Fairall 1984). Fecundity, here defined as the number of young per female, was determined from examination of road casualties $(n=80)$ and females shot for various reasons $(n=10)$ during the study period. Using the above data (age structure, fecundity and sex ratio) the number of births in the population was calculated as a check of the census data. The age structure of the population, directly after the birth pulse was recalculated using this data.

A previous analysis of population data of the same rest camp using a dynamic modelling technique, showed that the population increased exponentially from 1975 to 1983 at a rate $r$ of 0,24 , and that the age structure was stable (Fairall, Vermeulen \& Van der Merwe 1986). Subsequent to 1983 the population growth rate has decreased $(r=0,015)$ and a stable age structure could also be predicted from this model. These age structures were used to derive survival rates from life table analysis (Caughley 1977).

A simple simulation model where births (B) are computed as:

$$
\mathrm{B}=\sum_{\mathrm{i}=1}^{4} \mathrm{Ni} \times \mathrm{Fi} \times \mathrm{Pi}
$$

where $\mathrm{N}=$ Numbers in age group

$\mathrm{F}=$ Fecundity of age group

$\mathrm{P}=$ Percentage females in age group

and $\mathrm{N}_{1}=\mathrm{S}_{1} \times \mathrm{B}$

$\mathrm{N}_{2}=\mathrm{S}_{2} \times \mathrm{N}_{1}$

$\mathrm{N}_{3}=\mathrm{S}_{3} \times \mathrm{N}_{2}$

$\mathrm{N}_{4}=\mathrm{S}_{4} \times \mathrm{N}_{3}$

when $\mathrm{S}=$ Survival rate

was used to investigate the management options for this population. The model is initialised with the basic parameter for each growth situation or required management manipulation.

Simulated removal programmes were also calculated, where: (a) 27 (increase $/ 100$ when $r=0,24$ ) animals are removed in proportion to the age structure, from a starting population of 100 . (b) The 27 are removed from the 1st year age group and (c) both the older age groups are initially removed therafter $40 \%$ of the third year group and all four-year-olds are culled annually after the young are weaned.

\section{Results}

The population estimates derived from the September censuses, covering the period 1979-1986, are shown in Table 1. The population increased from ca. 92 in 1979 to ca. 175 individuals in 1983, therafter decreasing to 159 in 1985 (Table 1). Figure 2 shows the population changes over the period 1975 to 1986. Casual observations at the time estimated the population at approximately 30 individuals in 1975 . Because of the apparent low numbers present during that period, this was considered to be a reasonable estimate.

The age specific fecundity varied from 0 for the first year class to 4 for the $>4$ year class (Table 2). The sex ratio (Table 3 ) is distorted, in the younger age groups, with a preponderance of females evident up to three years of age. 
Table 1

Estimates of the Tsitsikamma Rest Camp rock dassie population in September, shortly before the birth pulse

\begin{tabular}{lcccc}
\hline \multirow{4}{*}{ Date } & \multicolumn{3}{c}{ Population estimate } & \\
\hline Sep 1979 & Mature & Immature & Total & Limits $^{\mathrm{a}}$ \\
Oct 1980 & 53 & 39 & 92 & $75-154$ \\
Sep 1981 & 60 & 61 & 121 & $110-300$ \\
Sep 1982 & 65 & 73 & 132 & $125-239$ \\
Sep 1983 & 74 & 75 & 149 & $128-166$ \\
Sep 1984 & 91 & 84 & 175 & $123-177$ \\
Sep 1985 & 95 & 70 & 165 & $164-165$ \\
Sep 1986 & 94 & 65 & 159 & $156-216$ \\
\end{tabular}

${ }^{a}$ Lower limit is the highest actual count recorded.

Higher limit is a calculated $95 \%$ confidence limit. (Robson \& Whitlock 1964)

The calculated age distributions of the studied population for the exponential growth phase $(1975$ - 1983) and the equilibrium situation (1983 - 1986) are depicted in Figure 3. This diagram also shows the calculated survival rates of each year class. These vary considerably as is to be expected from the differing growth rates.

Figure 2 shows the calculated population growth using the simulation model developed for the management investigation relative to the observed census values. The calculated values correspond fairly closely and lend some confidence to the use of the model for predicting management options.

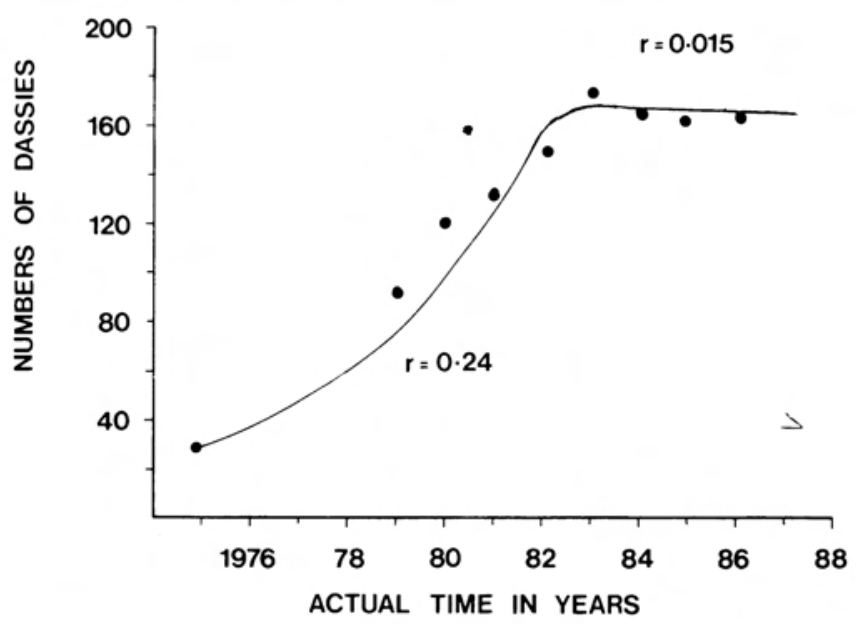

Fig. 2. Simulated population growth and actual population estimates (black circles) illustrating exponential growth from 1975 to 1982 and the development of an equilibrium after this period. Exponential and equilibrium simulations are calculated separately and combined in the figure. 
Table 2

Age specific fecundity of the Tsitsikamma Rest Camp rock dassie population. Fecundity in this study is measured as total number of young per female

\begin{tabular}{lrc}
\hline Age class & $\mathrm{n}$ & $\begin{array}{c}\text { Mean number of young } \\
\text { per female } \pm \text { S D }\end{array}$ \\
\hline 1 year & 10 & $0,0 \pm 0,0$ \\
2 years & 8 & $2,0 \pm 0,0$ \\
3 years & 12 & $2,4 \pm 0,5$ \\
4 years & 6 & $3,2 \pm 0,7$ \\
4 years & 2 & $4,0 \pm 0,0$ \\
\hline
\end{tabular}

Table 3

Age specific sex ratios of the Tsitsikamma Rest Camp rock dassie population

\begin{tabular}{crcc}
\hline Age class & $\mathrm{n}$ & Female & Male \\
\hline 1 & 14 & $85 \%$ & $15 \%$ \\
2 & 15 & $80 \%$ & $20 \%$ \\
3 & 15 & $70 \%$ & $30 \%$ \\
4 & 14 & $58 \%$ & $42 \%$ \\
$>4$ & 0 & $58 \%$ & $42 \%$ \\
\hline
\end{tabular}

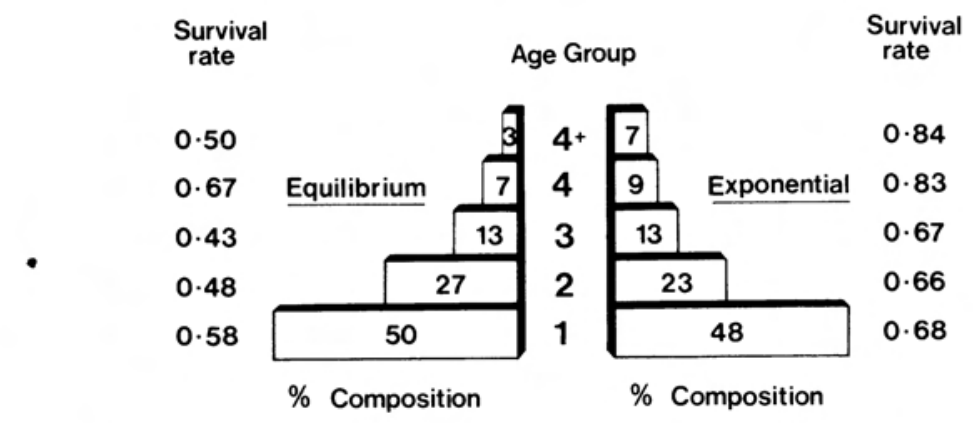

Fig. 3. Simulated equilibrium values, and age structure of the Tsitsikamma rock dassie population during the exponential growth phase. Survival rates are derived from these age structures.

Simulated population size after five years when using the exponential growth phase of the model and varying the different parameters (e.g. fecundity or sex ratios) by $10 \%$ is shown in Table 4 . The major factor influencing the final size of the population after five years appears to be the survival rate. The simulated removal programmes (Fig. 4) show that the age structures and population growth rates achieved vary tremendously. In two of the simulations population growth still 
Table 4

The effect of a $10 \%$ increase in individual demographic parameters on rock dassie population growth during a five year simulation. The standard run is based on the values for exponential increase as measured during the study

\begin{tabular}{lccc}
\hline Factor increased & Population size & $\%$ increase & Growth rate \\
\hline Standard run & 354 & & 0,25 \\
Fecundity & 415 & 17,2 & 0,29 \\
Survival & 564 & 59,3 & 0,35 \\
Female ratio & 419 & 18,4 & 0,29 \\
\hline
\end{tabular}
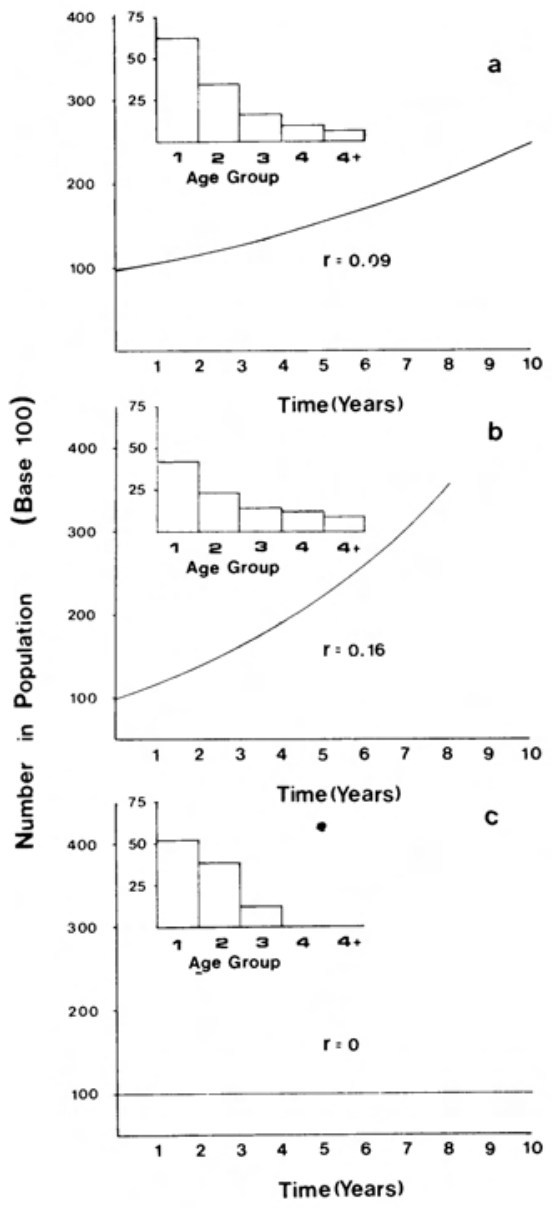

Fig. 4. Simulations representing different control strategies, starting from a population of 100 rock dassies in each instance. The stable age distributions predicted are also illustrated.

(a) $27(\mathrm{r}=0,24)$ dassies removed annually proportionately to the age structure,

(b) 27 dassies removed from the first year age group,

(c) the two oldest age groups and $45 \%$ of the third year age group are removed initially and therafter $45 \%$ of the third year age group is removed annually after the young are weaned. 
occurs even though the annual increase at the exponential growth rate $(r=0,24)$ is removed.

\section{Discussion}

Management of most wildlife populations in the past has been achieved by decisions taken on the basis of informed speculation. Managers react to some perceived problem and apply corrective measures on the information available and general ecological theory.

One field where the preceding comments are not true is fisheries management where books have been written on the subject (Beverton \& Holt 1957; Ricker 1975) and in the South African situation, sophisticated models are already employed (Butterworth \& Newman 1980). The reason for this dichotomy of approach is to be found in the fact that the fisheries manager is dealing with a commercially exploited resource, where large samples are normally available to provide demographic data and where over-exploitation has catastrophic economic effects.

Attempts to develop management models for South African game populations all reflect the shortage of solid long-term demographic parameters (Starfield, Smuts \& Shiell 1976; Starfield, Joubert, Cohen, Haque \& Stein 1980). In contrast the one long-term study that has been aimed at providing this type of demographic data (Owen-Smith 1984) gives the class of information that should be used for making management decisions.

The present study has a number of advantages: the rock dassies are accustomed to humans and are therefore easy to observe. They occur in a defined area and there is little if any emigration or immigration (Crawford \& Fairall 1984). This has enabled the accumulation of accurate data for the population.

The stabilisation of numbers that has occurred since 1983 is ascribed to saturation of optimal shelter and an increase in predation. Rock dassies are mainly diurnal, and human activity limits the day time entrance of predators such as the caracal Felis caracal Schreber, 1776, leopard Panthera pardus (Linnaeus, 1758), and even eagles. When optimal shelter is fully occupied the rock dassies have to use any shelter available and then become subject to predation at night. Increased sighting of both caracal and leopard have been reported by park staff in 1984 and 1985, and this is assumed to be due to the food source represented by the large rock dassie population.

The fact that the rock dassie population has stabilised naturally has removed some of the urgency that gave rise to the original idea of population management outlined in the introduction. If, as postulated, the population density is being controlled by caracal and leopard, the loss of these agents would lead to a rapid increase in numbers (Table 4) and a consequent need for management. This could easily happen, as the park adjoins a farming community, which has little sympathy for predators.

A prerequisite for population management is to define the purpose of control and the objectives to be attained. Caughley (1977) holds that there are basically 
three reasons for management: (1) raising the density of a small or declining population; (2) the exploitation of a population to take a sustained yield; and (3) the control of a population that is too dense, to stabilise or reduce its density. Goodman (1980) looks at the requirements for treating conditions 1 and 3 and provides guidelines for using modelling in management, based on reasonably sophisticated mathematics and intensive management.

In the present instance we are dealing with a population that could be approaching the limits of its environment in terms of damage to sensitive vegetation and unacceptable interaction with the tourists. This would be the reason for management. Defining the objectives is a more difficult exercise, and could vary in time, due to physical changes in the environment or policy decisions by the controlling administration. For the purpose of this study the objectives are defined as: (1) providing an interesting experience for the tourists by having a large population of visible animals; (2) limiting the number of rock dassies to a level where damage to sensitive vegetation will not occur. As both these objectives seem to be provided by the present population level, the required population size is in the region of 150 animals just before the birth pulse.

Manipulating the population to maintain the number of animals just before the birth pulse at about 150 can be attained either by shooting the required number or trapping and relocating them. How this is done is, however, critical.

In Table 4 it can be seen that when a change of equivalent magnitude is applied to the factors that determine population growth, survival rate emerges as the most sensitive component, as it results in nearly $60 \%$ increase in five years. Fecundity in this population is high and is unlikely to be affected by nutrition (Fairall, Vermeulen \& Van der Merwe 1986). Changing overall fecundity can therefore only be achieved by changing the age structure. Altering the sex ratio would have only a small effect on population growth (Table 4) and secondly, because it is such a distorted ratio (Table 3), attempting to manipulate the population by changing the age specific sex ratio could have drastic effects. Survival rate and age structure remain as the two factors that can be manipulated and they are related as a change in survival rates usually affects the age structure. This is illustrated in Figure 3 where the population at equilibrium has a younger age structure and different survival rates.

While a culling programme could be devised to decrease the population in the same relative frequencies as the equilibrium population it is rather obviously impractical in the present case and involves the removal of a large number of animals.

If growth approximates exponential conditions, as measured during the study, at the time when culling becomes necessary, the population will increase by 27 per hundred $(r=0,24)$. Just removing 27 animals would not necessarily achieve zero growth. This is illustrated in Figures $4 \mathrm{a}$ and $4 \mathrm{~b}$ where 27 animals are removed annually from the same initial population.

If the 27 are removed in proportion to the age classes a growth rate of $r=0,09$ is still achieved, which means that the population will double in seven years. When the 27 rock dassies are removed only from the first year class, a much more mature 
age structure results and the population grows at a rate of $r=0,16$ and doubles in four years.

Goodman (1980) shows that the answer to the management problem is to tailor the population age structure to the stable form at the inception of culling and then taking a constant proportion of certain age classes annually. Beddington \& Taylor (1973) illustrate that optimal harvesting is achieved by removing one age class totally and partially harvesting one other age class. Even though optimal production is not necessary here, this approach has certain practical advantages in the present case.

The age structure and survival rates achieved in the equilibrium population (Fig. 3) show a decrease in the older age classes and increased mortality at this level. The older age classes have a much higher fecudity so that removing them tends to slow population growth. Because there are fewer old animals, however, removing only the two older groups does not achieve zero growth. When both the oldest age classes are taken out initially, and $40 \%$ of the 3 year old category and all older rock dassies are removed annually just after the young are weaned, a stable age distribution and zero growth can be simulated. This condition is shown in Figure $4 \mathrm{c}$ where a very young population is evident. This has the advantage that when culling is stopped, the population will quickly recover, and is therefore safer than a preponderantly "old" population. The greatest advantage from a management point of view, however, is that only 20 animals per hundred need be removed annually. To stabilise at 150 rock dassies, (the suggested carrying capacity at Tsitsikamma), 14 three-year-old rock dassies and 17 four-year-olds would have to be removed annually.

At this point it must be stressed that the simulation model is very simple and the results obtained depend on the parameters used not changing as the population is manipulated. It has been pointed out that fecudity is likely to be maximal and it is unlikely that the control programme will change this. If the older males are removed, however, juvenile male survival could increase dramatically and this would alter the whole picture. It is also likely that this type of manipulation would affect survival rates in general and these would invalidate the results of the model.

The value of the approach adopted in this study implies that a culling programme planned this way can be monitored with ease. Counts such as have formed the basis of this study can be repeated annually with little effort. From these counts, changes in fecundity and survival would soon become apparent. The simplicity of the model allows these changes to be incorporated in planning a more refined strategy. This approach has a greater chance of success and leads to improved management efficiency, when compared to culling decisions based on perceived excesses of animals.

\section{Acknowledgements}

The support of the Department of Agriculture, the National Parks Board of Trustees, and the Mammal Research Institute has made this study possible and it is gratefully acknowledged. This work requires long series of data and is not productive initially which makes their continued 
support the more valuable. Rob Crawford did much of the data gathering and his contribution is gratefully recorded.

\section{References}

BEDDINGTON, J.R. and D.B. TAYLOR. 1973. Optimal age specific harvesting of a population. Biometrics 29: $801-809$.

BEVERTON, R.J.H. and S.J. HOLT. 1957. On the dynamics of exploited fish populations. Fisheries Investigation Series II, vol. 19. London: Ministry of Agriculture, Fisheries and Food.

BUTTERWORTH, D.S. and C.G. NEWMAN. 1980. The application of modelling to southern African fisheries management. Pp. 305-337. In: GETZ, W.M. (ed.). Mathematical Modelling in Biology and Ecology. Lecture Notes in Biomathematics. Vol. 33. Berlin: Springer-Verlag.

CAUGHLEY, G. 1977. Analysis of Vertebrate Populations. New York: John Wiley.

CRAWFORD, R.J.M. and N. FAIRALL. 1984. Male rock hyraxes Procavia capensis return to former home ranges after translocation. Koedoe 27: 151-153.

FAIRALL, N. 1980. Growth and age determination in the hyrax Procavia capensis. S. Afr. J. Zool. 15: 16-21.

FAIRALL, N. and R.J.M. CRAWFORD. 1983. Application of the Robson-Whitlock technique to estimate hyrax Procavia capensis numbers. S. Afr. J. Wildl. Res. 13: 25-26.

FAIRALL, N., P. VERMEULEN and M. VAN DER MERWE. 1986. A general model of population growth in the hyrax, Procavia capensis. Ecol. Mod. 34: 115-132.

GOODMAN, D. 1980. Demographic intervention for closely managed populations. Pp. 171 - 195. In: SOULE, M.E. and B.A. WILCOX, (eds.). Conservation Biology. Sunderland: Sinauer Associates.

HANSE, W.A. 1962. Inleidende studie van die dassie Procavia capensis, sy verhouding tot die boerdery in Suid-Afrika en beheermetodes. Kaapse Dept. Natuurbewaring. Jaarverslag No. 19: $108-121$.

KOLBE, F.F. 1967. A plea for dassies. Afr. Wildl. 21: 237-248.

OWEN-SMITH, N. 1984. Demography of greater kudu Tragelaphus strepsiceros in relation to rainfall. Acta Zool. Fenn. 172: 197-199.

RICKER, W.E. 1975. Computation and interpretation of the statistics of fish populations. Bull. Fish. Res. Brd. Canada. 191.

ROBSON, D.S. and J.H. WHITLOCK. 1964. Estimation of a truncation point. Biometrica 51: $33-39$.

STARFIELD, A.M., G.L. SMUTS and J.D. SHIELL. 1976. A simple wildebeest population model and its application. Sth. Afr. J. Widll. Res. 6: 95-98.

STARFIELD, A.M., S.C.J. JOUBERT, B.H. COHEN, E.K. HAQUE and D.J. STEIN. 1980. An exploratory model of impala population dynamics. Pp. $338-355$. In: GETZ, W.M. (ed.). Mathematical Modelling in Biology and Ecology. Lecture Notes in Biomathematics. Vol. 33. Berlin: Springer-Verlag. 